\title{
A UTILIZAÇÃO DA HISTÓRIA DA MATEMÁTICA COMO ALTERNATIVA METODOLÓGICA DE ENSINO DE GEOMETRIA PLANA: ÁREA E PERÍMETRO
}

\section{THE HISTORY OF USE OF MATHEMATICS AS AN ALTERNATIVE METHODOLOGY OF TEACHING GEOMETRY PLANE: AREA AND PERIMETER}

\author{
Bruno Sebastião Rodrigues da Costa \\ Instituto de Educação Matemática e Científica-Programa de Pós-Graduação em \\ Docência em Educação em Ciências e Matemáticas (UFPA)
}

Selma de Nazaré Vilhena Machado ${ }^{2}$

Universidade do Estado do Pará (UEPA)

Alessandra Maués Quaresma

Universidade do Estado do Pará (UEPA)

\section{Resumo}

A História da Matemática acompanha a humanidade desde o início das organizações sociais, auxiliando o homem a resolver problemas, construir modelos, estabelecer associações, relações e quantificações entre os conhecimentos, sendo um instrumento que contribui no processo de ensino e aprendizagem. Nesse sentido, o referido trabalho apresenta os resultados de uma pesquisa realizada por duas alunas do curso de Licenciatura Plena em Matemática de uma Instituição de Ensino Superior, localizado no município de Moju. O assunto envolvido refere-se a Geometria Plana, especificamente aos conteúdos de área e perímetro. A pesquisa ocorreu na Escola Estadual de Ensino Fundamental e Médio Prof ${ }^{\circ}$. Bernardino Pereira de Barros na turma do $9^{\circ}$ ano com 23 alunos no município de Abaetetuba - Pará. Com isso, objetivamos mostrar a importância do ensino da História da Matemática como instrumento de incentivo e motivação no processo de ensino e aprendizagem de Geometria. Tivemos como metodologia a História da Matemática, utilizando como ferramenta uma sequência de atividades para o ensino de área e perímetro, a qual foi balizada por meio da Engenharia Didática de segunda geração, evidenciadas pelas análises preliminares, analise a priori, experimentação e analise posteriori e validação. Dessa forma, apresentaremos os dados coletados, por meio de quadros, onde tivemos melhorias no processo de ensino e aprendizagem de área e

\footnotetext{
${ }^{1}$ matbrunocosta@gmail.com

2 selmamachado1997@gmail.com

3 alessandraquaresma790@gmail.com
} 
perímetro, concluindo que o uso da História Matemática contribui positivamente para esse processo. Nessa perspectiva, a História da Matemática é uma das possibilidades de se ensinar a matemática, pois a torna mais próxima das realizações do cotidiano dando aos alunos um maior entendimento da sua presença quanto parte da sociedade para o surgimento da matemática.

Palavras-chave: Educação matemática; Ensino e Aprendizagem; Geometria Plana; História da Matemática.

\begin{abstract}
The History of Mathematics accompanies mankind from the beginning of social organizations, helping mankind to solve problems, build models, establish associations, relationships and quantifications between knowledge, being an instrument that contributes to the process of teaching and learning. In this sense, this work presents the results of a research carried out by two students of the Full Mathematics Degree course of a Higher Education Institution, located in the municipality of Moju. The subject involved refers to Flat Geometry, specifically to area and perimeter contents. The research took place at the State School of Elementary and High School Prof ${ }^{\circ}$ Bernardino Pereira de Barros in the 9th grade class with 23 students in the municipality of Abaetetuba - Pará. With this, we aim to show the importance of teaching the History of Mathematics as an instrument of incentive and motivation in the process of teaching and learning Geometry. Our methodology was the History of Mathematics, using as a tool a sequence of activities for the teaching of area and perimeter, which was based on second-generation Didactic Engineering, evidenced by preliminary analysis, a priori analysis, experimentation and posteriori analysis and validation. In this way, we will present the data collected, by means of tables, where we had improvements in the teaching and learning process of area and perimeter, concluding that the use of Mathematical History contributes positively to this process. From this perspective, the History of Mathematics is one of the possibilities of teaching mathematics, because it brings it closer to the achievements of everyday life, giving students a greater understanding of their presence as part of society for the emergence of mathematics.
\end{abstract}

Keywords: Mathematics Education; Teaching and Learning; Plane Geometry; the History of Mathematics.

\title{
Introdução
}

A geometria está presente em diferentes formas e em diversas situações em nosso cotidiano, fazendo parte da vida do ser humano desde os tempos mais remotos, tornandose assim um dos ramos mais antigos da matemática. Com o auxílio da geometria e os conhecimentos adquiridos no dia a dia, é possível que o aluno desenvolva competências e habilidades que os ajudarão na vida escolar como também no seu cotidiano.

Compartilhando o mesmo pensamento, Passos (2000) nos mostra que a geometria é uma importante ferramenta "para a descrição e a inter-relação do homem com o espaço 
A utilização da história da matemática como alternativa metodológica de ensino de geometria plana: área e perímetro

Bruno Sebastião Rodrigues da Costa, Selma de Nazaré Vilhena Machado e Alessandra Maués Quaresma

que vive". Ainda para o autor, a geometria é fundamental para a formação do aluno, pois é a "parte da matemática mais intuitiva, concreta e ligada a realidade" (PASSOS, 2000, p. 49).

Desse modo, seu conhecimento se torna indispensável para o desenvolvimento do ser humano, pois ajuda na compreensão do mundo, desenvolve o raciocínio lógico e proporciona um melhor entendimento de outras áreas do conhecimento.

Com esse entendimento, a História da Matemática é um instrumento que proporciona ao aluno uma melhor compreensão, pois Fossa (2008), relata que a História da Matemática traz múltiplas vantagens na construção de atividades, onde vai propiciar ao aluno a participação no desenvolvimento matemático, com isso aumentará o interesse dele sobre o estudo o que vai fazer com se tenha um melhor desempenho.

Segundo Fossa (2008)

A história proporciona ao aluno o significado da investigação matemática proposta e, em consequência, a mesma deixa de ser algo misterioso e ininteligível. Ao enfocar elementos pré-formais e, frequentemente, aplicados da matemática, a história leva o aluno a pensar sobre conceitos matemáticos sem a linguagem técnica que poderá ser uma barreira inicial ao seu entendimento. (FOSSA, 2008, p. 13)

Assim caracterizado por Mendes (2010), a investigação em História da Matemática em sala de aula, pode vim a desenvolver a criatividade dos alunos, estimulando a aprendizagem dos mesmos, onde isso venha a acarreta na formulação de ideias matemáticas através de pesquisas, cujo os alunos cheguem a sentir-se como descobridores de cada tema investigado.

Para Mendes (2010)

[...], os estudantes desenvolverão sua autoconfiança de forma crescente e
amadurecida, principalmente nos momentos de investigação e na socialização
de suas experiências com os outros colegas envolvidos no processo
investigatório em sala de aula. Isso implicará formar estudantes mais criativos
e capazes de encorajar-se na demonstração dos princípios matemáticos
percebidos durante a investigação histórica. Isso certamente evidenciará a
natureza viva e globalizante da Matemática incluída na investigação, por meio
de conexões entre a Matemática e outras disciplinas acadêmicas que podem
fornecer ligações entre o contexto externo e a sala de aula. (MENDES, 2010,
p. $41-42$ )

Nesse sentido, a presente pesquisa objetiva mostrar a importância do ensino da História da Matemática como instrumento de incentivo e motivação no processo de 
A utilização da história da matemática como alternativa metodológica de ensino de geometria plana: área e perímetro

Bruno Sebastião Rodrigues da Costa, Selma de Nazaré Vilhena Machado e Alessandra Maués Quaresma

ensino e aprendizagem de Geometria, para de área e perímetro, onde os resultados foram satisfatórios e serão mostrados por meio de quadros.

Compreendendo a relevância de se almejar maneiras de se ensinar a Geometria, buscamos por meio da História da Matemática uma alternativa metodológica, assim também como autores que afirma a relevância do uso da mesma em sala de aula.

Com isso, o conhecimento matemático pode ser apresentado aos educandos como historicamente construído e em permanente transformação. O contexto histórico possibilita ver a Matemática em sua prática filosófica, científica e social e contribui para a compreensão do lugar que ela tem no mundo (BRASIL, 1998).

\section{A Geometria e seu percurso}

Os primeiros conhecimentos geométricos surgiram em meio as necessidades encontradas pelo homem em compreender melhor o ambiente onde vivia. Segundo Eves (1997), os conceitos mais primitivos encontrados sobre a geometria são muito antigos, originando-se através de simples observações de figuras, reconhecendo e comparando formas e tamanhos. Daí a origem da palavra "geometria" do grego geo = terra + metria $=$ medida que significa medição de terra.

As primeiras considerações que o homem fez a respeito da geometria são, inquestionavelmente, muito antigas. Parecem ter se originado de simples observações provenientes da capacidade humana de reconhecer configurações físicas, comparar formas e tamanhos. (EVES, 1997, p. 1).

Ainda para Eves (1997), a necessidade do homem em delimitar terras ocasionou o surgimento de uma geometria que se caracterizava pelo traçado de desenho de formas, fórmulas, cálculo de medidas de comprimento de áreas, volumes, etc. Tendo assim, nessa época, o desenvolvimento da noção de figuras geométricas como, retângulo, quadrado, triângulos e outros conhecimentos simples, como noção de vertical, paralela e perpendicular, teriam aparecidos pela construção de muros e moradias.

Inúmeras circunstâncias da vida, até mesmo do homem mais primitivo, levavam a um certo montante de descobertas geométricas subconscientes. [...]. A necessidade de delimitar a terra levou à noção de figuras geométricas simples, tais como retângulo, quadrado e triângulos. Outros conceitos geométricos simples, como as noções de vertical, paralela e perpendicular, teriam sido sugeridos pela construção de muros e moradias. (EVES, 1997, p. $1-2)$ 
A utilização da história da matemática como alternativa metodológica de ensino de geometria plana: área e perímetro

Bruno Sebastião Rodrigues da Costa, Selma de Nazaré Vilhena Machado e Alessandra Maués Quaresma

É notório que, no decorrer da história, a geometria sempre teve grande influência e importância, ajudando o homem em suas descobertas. Hoje vemos que, mesmo com o passar do tempo, sua relevância não se limitou e continua sendo um componente essencial para a construção do conhecimento.

\section{O Ensino da Geometria}

A partir do movimento da matemática moderna (década de 70), o ensino da geometria foi colocado em segundo plano. Dessa maneira os livros didáticos reservam nos últimos capítulos os conteúdos referentes a esse campo.

No Brasil, Pavanello (1989) afirma que o ensino de geometria se dá de forma diferenciada "a tradicional dualidade do ensino brasileiro até que poderia, em termos de ensino da matemática, ser colocada como: escola onde se ensina geometria (escola para elite) e escola onde não se ensina geometria (escola para o povo). (PAVANELLO, 1989, p.166)", pois para ele, o abandono do ensino de geometria se inicia primeiro nas escolas públicas e se torna mais intensa do que nas escolas privadas, diferenciando-as entre ensino para a elite e ensino para o povo.

Como afirma os Parâmetros Curriculares Nacionais (PCNs) de Matemática para os anos finais, a geometria é um elemento importante para resolvermos situações do nosso cotidiano, que também podemos levar para fora da escola. Essa prática de ensino pode ser situada de várias atividades que o aluno realiza no seu dia a dia, as quais envolvem matemática:

\footnotetext{
O estudo da Geometria é um campo fértil para trabalhar com situaçõesproblema [...]. O trabalho com noções geométricas contribui para a aprendizagem de números e medidas, pois estimula o aluno a observar, perceber semelhanças e diferenças, identificar regularidades etc. (BRASIL, 1998, p. 51).
}

Ainda para os PCNs, a geometria "desempenha um papel fundamental no currículo, na medida em que possibilita ao aluno desenvolver um tipo de pensamento particular para compreender, descrever e representar, de forma organizada, o mundo em que vive" (BRASIL, 1998, p. 122), por esse motivo deve ser ensinada e não excluída da grade curricular do aluno.

No ensino fundamental é importante que o conhecimento matemático em seus diversos campos possibilitem o aluno a relacionar observações empíricas as 
A utilização da história da matemática como alternativa metodológica de ensino de geometria plana: área e perímetro

Bruno Sebastião Rodrigues da Costa, Selma de Nazaré Vilhena Machado e Alessandra Maués Quaresma

representações do mundo real, para que assim os alunos se tornem capazes de fazer deduções e suposições.

No Ensino Fundamental, essa área, por meio da articulação de seus diversos campos - Aritmética, Álgebra, Geometria, Estatística e Probabilidade, precisa garantir que os alunos relacionem observações empíricas do mundo real a representações (tabelas, figuras e esquemas) e associem essas representações a uma atividade matemática (conceitos e propriedades), fazendo induções e conjecturas. (BRASIL, 2017, p. 263)

Dessa forma, a contextualização se mostra importante para que essas observações se tornem possíveis por situações cotidianas do aluno, onde ele consegue observar por si só o quanto a matemática se faz presente ao seu redor.

No ensino fundamental, anos finais, é interessante destacar algumas habilidades a serem alcançados quanto o ensino de geometria que vão desde a capacidade de demonstração simples do assunto abordado até a construção do raciocino hipotéticodedutivo do aluno.

Esses conceitos devem ter destaque nessa fase do Ensino Fundamental, de modo que os alunos sejam capazes de reconhecer as condições necessárias e suficientes para obter triângulos congruentes ou semelhantes e que saibam aplicar esse conhecimento para realizar demonstrações simples, contribuindo para a formação de um tipo de raciocínio importante para a Matemática, o raciocínio hipotético-dedutivo. (BRASIL, 2017, p.270)

Com isso, a geometria não deve se limitar apenas em aplicação de fórmulas de cálculo de área e volume, como também a aplicação numérica de teoremas. Visto que desde os tempos mais antigos, cálculos de áreas, por exemplo, eram realizados por deduções sem a utilização de fórmulas, obtendo um resultado verídico.

Essas habilidades podem ser alcançadas por ferramentas e métodos de ensino diferente do tradicional, onde irá possibilitar que o aluno crie seu próprio pensamento crítico assim também como o seu conceito sobre o que está sendo ensinado.

\section{Áreas e Perímetros}

No ensino fundamental, anos finais, observamos a geometria nos capítulos finais dos livros didáticos, o que acaba prejudicando seu ensino, pois o tempo se apresenta curto, 
A utilização da história da matemática como alternativa metodológica de ensino de geometria plana: área e perímetro

Bruno Sebastião Rodrigues da Costa, Selma de Nazaré Vilhena Machado e Alessandra Maués Quaresma

tornando-se superficial, principalmente no que se refere aos conceitos de área e perímetro de figuras planas.

O livro é um dos recursos ou o único que o professor utiliza para ensinar, ele apresenta de forma direta o conteúdo de área e perímetro, não há um conceito voltado para uma aplicação do cotidiano do aluno. O que se mostra são as figuras seguidas de suas fórmulas para cálculo de área e perímetro. Por não haver essa contextualização e distinção, os alunos acabam misturando área com perímetro, ou que a área é a soma de dois lados.

O que observasse quanto ao ensino de área e perímetro, é que o aluno apresenta certa dificuldade em aprender o seu conteúdo, causando assim uma confusão durante o seu estudo. Segundo Lima (2002) é preciso evidenciar a diferença entre as noções de área e perímetro, para então evitar tais confusões.

[...] o cálculo de área e perímetro é usualmente ensinado através de fórmulas de área, que são funções que fornecem a medida de área, em termos do comprimento de segmentos associados a figura. Este procedimento é indispensável para o cálculo de áreas, mas, em sua utilização, tem sido verificada persistentes dificuldades entre os alunos. Uma delas é a confusão entre área e perímetro; outra é a extensão indevida da validade das fórmulas de área: a área de um paralelogramo é o produto dos lados. (LIMA apud BELLEMAIN e LIMA, 2002, p.27).

Para o estudo de área e perímetro de um objeto, é preciso primeiramente compreender a noção de espaço e forma. Esse conhecimento pode ser repassado através do uso de matérias concreto, onde é preciso que o aluno consiga distinguir, por exemplo, o quadrado do retângulo assim também como suas propriedades, pois temos que ambos são quadriláteros possuindo em comum seus ângulos, para que, a partir daí possa efetuar o cálculo.

\section{O uso da História da Matemática como recurso didático}

A afirmação de que a Matemática é "uma ciência voltada unicamente para os número e grandeza" já não encontra mais adeptos desde as últimas décadas do final do século passado, registra Boyer (2002). Hoje já é notável que a Matemática vai além desses aspectos e sofre mutações conforme as necessidades sociais dos indivíduos, de acordo com Rosa Neto (1988), pois se desenvolve e evolui. Essa ideia é ratificada por Saito e

Dias (2013) quando afirmam "que o conhecimento matemático afigurou-se de forma 
A utilização da história da matemática como alternativa metodológica de ensino de geometria plana: área e perímetro

Bruno Sebastião Rodrigues da Costa, Selma de Nazaré Vilhena Machado e Alessandra Maués Quaresma

diferenciada em determinados momentos da história, atendendo a uma necessidade não só interna, como, também, a uma demanda extramatemática."

A História da Matemática como instrumento didático, é um método de conhecimento essencial para que o aluno compreenda o mundo. No entanto, o ensino da Matemática tem passado por certas dificuldades já que as maiorias dos alunos não gostam dessa disciplina e os professores não fazem nada para mudar essa concepção. Segundo Schimidt, Pretto e Leivas (2006):

\footnotetext{
Ela é descrita como um campo de conhecimento fundamental para que o ser humano compreenda o mundo. Porém, o ensino dessa disciplina tem passado por certos problemas quando os alunos dizem que não sabem ou não gostam dela ou quando os professores relatam sobre sua prática de ensino. (SCHIMIDT, PRETTO; LEIVAS, 2006, p. 4)
}

Outra forma de participação da História, manifestada na proposta dos PCN para o ensino da Matemática, diz respeito ao uso de problemas históricos, pois considera que os conceitos matemáticos devem ser mostrados mediante a exploração de problemas, ou seja, situações em que os alunos precisem desenvolver estratégias para resolvê-las.

Para D’Ambrosio (1999), em Matemática é impossível discutir práticas educativas que se fundamentem na cultura, em estilos de aprendizagem e nas tradições sem recorrer à História, que compreende o registro desses fundamentos. Em suas palavras: "desvincular a Matemática das outras atividades humanas é um dos maiores erros que se pratica particularmente na Educação Matemática".

Além do mais, é quase impossível dissociar as raízes da Matemática com a própria história da humanidade, afirma D’Ambrósio (1999), reforçando, assim, o valor de ensinar a disciplina recorrendo a fundamentos históricos e suas interpretações. Lopes e Ferreira (2013) discorrem com propriedade a respeito da utilização da História da Matemática como recurso metodológico de ensino, à medida que essa abordagem possibilita aulas mais motivadoras, dinâmicas, interessantes, pois ao perceber a fundamentação histórica da matemática, o professor tem em suas mãos ferramentas para mostrar o porquê de estudar determinados conteúdos, fugindo das repetições mecânicas de algoritmos.

Por esse motivo, ao utilizar o uso da História da Matemática, o professor deverá verificar o seu objetivo, dinamizando a aula, para que os conteúdos ministrados façam sentido. Sendo primordial que o professor consiga repassar aos estudantes a compreensão de que a Matemática está em todas as situações da vida do ser humano, pois suas raízes 
A utilização da história da matemática como alternativa metodológica de ensino de geometria plana: área e perímetro

Bruno Sebastião Rodrigues da Costa, Selma de Nazaré Vilhena Machado e Alessandra Maués Quaresma

estão assentadas no cotidiano e são indispensáveis ao desenvolvimento e conquista tecnológica (SANTOS, 2006).

Sobre esse assunto, Mendes (2001) afirma que é importante que o professor conheça profundamente o tópico histórico que deseja apresentar aos alunos, para que possa segurar as discussões engendradas por esse, na realização das atividades. A falta de esclarecimento sobre o conteúdo histórico pode prejudicar o desenvolvimento das atividades e consequentemente influenciar no resultado dos objetivos previstos.

\section{Metodologia}

O trabalho foi desenvolvido na Escola Estadual de Ensino Fundamental e Médio Prof. Bernardino Pereira de Barros, localizado na Rua Magno de Araújo, 1485 na cidade de Abaetetuba-PA, em uma turma do $9^{\circ}$ ano composta por 23 alunos. Para realização da pesquisa foi preciso 24 aulas, a qual levou um mês e duas semanas começando no mês de novembro e terminando na terceira semana de dezembro, os resultados foram coletados por meio de uma sequência de atividades e balizado na engenharia didática que segundo geração, (ALMOULOUD 2007 apud DE ALMEIDA, 2011, p.5), ela "se apoia em um esquema experimental baseado na concepção, realização, observação e análise de sequências de ensino, além da validação, que é a comprovação ou não das hipóteses assumidas no estudo, mediante as análises a priori e a posteriori."

A seguir será apresentado os momentos que explicarão como foi apresentado e desenvolvido o trabalho.

- Inicialmente, buscamos analisar os conhecimentos que os alunos possuíam sobre o assunto, por meio de uma apostila contendo cinco questões sobre área e perímetro.

- No segundo, foi apresentado a turma um vídeo que descrevia a história da geometria. Nele, era possível observar a origem da geometria, o porque ela surgiu, o que influenciou sua origem, sua aplicação no dia a dia, seu desenvolvimento até os dias atuais para que, desse modo o aluno se interessasse e motivasse em buscar mais conhecimento sobre a matemática.

- Já no terceiro momento adentramos a parte das figuras planas apresentando-as com o auxílio de um slide. Como a maioria dos alunos ainda apresentava dúvidas em identificar e caracterizar as figuras geométricas planas, foi sucinto o auxílio do professor para que alcançássemos todos da turma. Após esclarecido o assunto, mostramos para os 
A utilização da história da matemática como alternativa metodológica de ensino de geometria plana: área e perímetro

Bruno Sebastião Rodrigues da Costa, Selma de Nazaré Vilhena Machado e Alessandra Maués Quaresma

alunos as figuras que abrangeríamos durante nossos cálculos, triangulo, retângulo, quadrado, losango e trapézio. Em continuidade, explicamos o significado de geometria plana e os conceitos que ela envolve, ressaltando as figuras a serem trabalhadas, suas definições e classificação quanto ao lado e ângulo.

- No quinto momento foi utilizado o ladrilhamento como ferramenta, pois fora iniciado os cálculos de área e perímetro.

- Após o uso do ladrilhamento, aplicamos o Gibi. Essa ferramenta foi organizada por nós com um cenário da História em Quadrinhos da turma da Mônica. Como ele seria dado aos alunos, buscamos agrupar tudo que fora apresentado durante nossa sequência de atividades, desde a história da geometria até os problemas sobre área e perímetro.

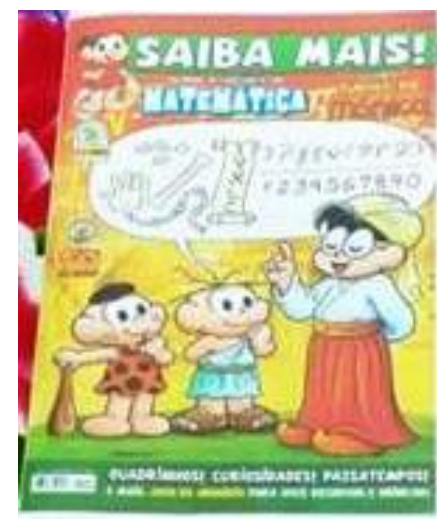

Figura 1 - História em Quadrinhos Fonte: Os autores (Dezembro 2018)

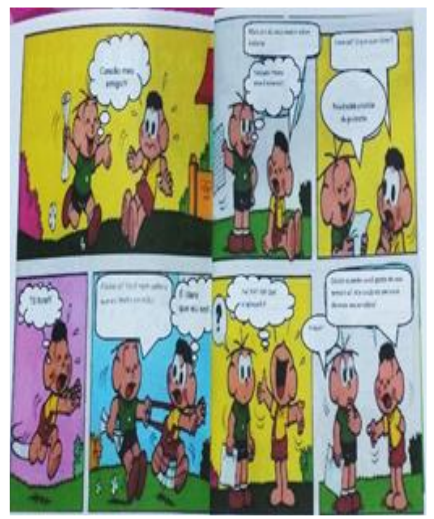

Figura 2 - História em Quadrinhos Fonte: Os autores (Dezembro 2018)

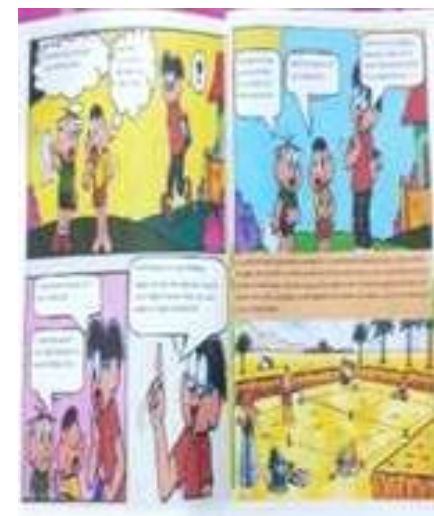

Figura 3 - História em Quadrinhos Fonte: Os autores (Dezembro 2018)

Após a distribuição do Gibi, explicamos a finalidade dessa ferramenta que era de ensinar os alunos a calcularem a área e perímetro de figuras, agora com valores maiores do que os usados no ladrilhamento.

- Por fim, foi realizada um teste a posteriori, com o intuito de verificar se a sequência de atividades utilizando a História da Matemática contribuiu no processo de ensino e aprendizagem.

\section{Resultados e discussões}

Durante a aplicação da sequência de atividades foi perceptível muitas dificuldades, uma delas centrava-se na utilização dos instrumentos matemáticos, o 
A utilização da história da matemática como alternativa metodológica de ensino de geometria plana: área e perímetro

Bruno Sebastião Rodrigues da Costa, Selma de Nazaré Vilhena Machado e Alessandra Maués Quaresma

transferidor e compasso. Os alunos não conseguiam manipulá-los para encontrar os ângulos das figuras, sendo que ele é indispensável no ensino da geometria plana.

A seguir apresentaremos o quadro com os resultados dos testes a priori e a posterior que foram aplicados durante o projeto e mostrarão o desempenho obtido neste processo.

\begin{tabular}{|c|c|c|c|c|c|c|c|c|}
\hline & \multicolumn{4}{|c|}{ Certo } & \multicolumn{4}{|c|}{ Errado } \\
\hline & \multicolumn{2}{|l|}{ Área } & \multicolumn{2}{|c|}{ Perímetro } & \multicolumn{2}{|l|}{ Área } & \multicolumn{2}{|c|}{ Perímetro } \\
\hline & Priori \% & Posteriori \% & $\begin{array}{c}\text { Priori } \\
\%\end{array}$ & $\begin{array}{c}\text { Posteriori } \\
\%\end{array}$ & $\begin{array}{c}\text { Priori } \\
\%\end{array}$ & $\begin{array}{c}\text { Posteriori } \\
\%\end{array}$ & $\begin{array}{c}\text { Priori } \\
\%\end{array}$ & Posteriori \% \\
\hline Q. 1 & 0 & 78 & 43 & 100 & 100 & 12 & 57 & 0 \\
\hline Q. 2 & 9 & 100 & 87 & 100 & 91 & 0 & 13 & 0 \\
\hline Q. 3 & 0 & 100 & 13 & 78 & 100 & 0 & 83 & 12 \\
\hline Q. 4 & 0 & 87 & 9 & 87 & 100 & 13 & 91 & 13 \\
\hline Q. 5 & 0 & 100 & 83 & 100 & 100 & 0 & 17 & 0 \\
\hline
\end{tabular}

Observamos que após a sequência de atividades foi possível amenizar os erros encontrados na aprendizagem de área e perímetro, pois os alunos já haviam entendido o assunto, assim conseguiam associar as fórmulas às suas figuras. Dessa forma podemos perceber que aumentou o percentual de acertos tanto em área quanto em perímetro, pois o sucesso mínimo corresponde a $78 \%$ o que a priori era equivalente a $0 \%$. Sendo assim, constatamos que o trabalho realizado com a turma foi significativo, trazendo resultados positivos, pois o número de acertos nas questões foi maior que os de erros principalmente no que se refere as questões de área.

Nessa perspectiva, a História da Matemática é uma das possibilidades de buscar outra forma de entender a matemática, pois a aproxima das realizações no cotidiano dando ao aluno uma visão maior de sua participação quanto parte da sociedade para o surgimento da matemática.

\section{Considerações Finais}

Diante do exposto, compreendemos que o ensino de geometria é de suma importância na vida de todo ser humano, pois vivemos cercados de figuras e formas geométricas. É com a geometria que o educando diferencia o espaço e forma de tudo que a rodeia.

É evidente que a História da Matemática é fundamental na vida dos seres humanos, por isso criamos uma sequência de atividades de modo que auxiliasse o 
A utilização da história da matemática como alternativa metodológica de ensino de geometria plana: área e perímetro

Bruno Sebastião Rodrigues da Costa, Selma de Nazaré Vilhena Machado e Alessandra Maués Quaresma

professor na explicação da geometria plana nos conteúdos de área e perímetro. Nosso objetivo, ao utilizar essa ferramenta foi alcançado, pois, despertou no aluno o interesse pelo contexto histórico da Matemática assim também como ajudá-lo a desenvolver seu próprio conceito sobre os assuntos de uma forma diferente e divertida, por meio da História da Matemática.

Assim, almejamos que a História da Matemática não se limite apenas como uma disciplina presente na vida acadêmica do professor, mas que este veja ela como uma alternativa metodológica de ensino explorando-a na sala de aula com o aluno.

\section{Referências}

ALMOULOUD, Saddo Ag. et al. A geometria no ensino fundamental: reflexões sobre uma experiência de formação envolvendo professores e alunos. Revista Brasileira de Educação. Rio de Janeiro: ANPEd, nº 27, p. 94-108, 2004.

BRASIL. Secretaria de Educação Fundamental. Parâmetros Curriculares Nacionais: Matemática. Brasília: MEC / SEF, 1998.

BOYER, Carl B. História da matemática. 2. ed. Tradução de Elza F. Gomide. São Paulo: Editora Edgard Blücher Ltda., 2002.

BELLEMAIN, P.; LIMA, P. Um estudo da noção de grandeza e implicações no Ensino Fundamental. Ed. Geral: John A. Fossa. Natal: SBHMat, 2002.

BRASIL. Base Nacional Comum Curricular. Brasília: MEC, 2017.

D’AMBROSIO, Ubiratan. A história da matemática: questões historiográficas e políticas e reflexos na Educação Matemática. In: BICUDO, M. A. V.(org.). Pesquisa em Educação Matemática: concepções e perspectivas. São Paulo: UNESP, 1999.

EVES, H.. Introdução a História da Matemática. Campinas, SP. Editora Unicamp, 1997.

FOSSA, John A. Matemática, História e Compreensão. Revista Cocar. UEPA, v.2. p. 715. 2008. Disponível: https://paginas.uepa.br/seer/index.php/cocar/article/view/77; acesso em 17.07.2017

LOPES, L. S.; FERREIRA, A. L. A. Um olhar sobre a história nas aulas de matemática. ABAKÓS - Instituto de Ciências Exatas e Informática. Belo Horizonte, v. 2, n. 1. 2013.

MENDES, I. A. O uso da história da matemática: reflexões teóricas e experiências. Belém: EDUEPA, 2001. 
A utilização da história da matemática como alternativa metodológica de ensino de geometria plana: área e perímetro

Bruno Sebastião Rodrigues da Costa, Selma de Nazaré Vilhena Machado e Alessandra Maués Quaresma

MENDES, Iran Abreu. A Investigação Histórica na Formação de Professores de Matemática. Revista Cocar. UEPA.

PASSOS, C.M.B. Representações, interpretações e prática pedagógica: a geometria na sala de aula. Tese de doutorado (Universidade Estadual de Campinas - Faculdade de educação), 2000.

PAVANELO, M. R. (1989) O abandono do ensino de Geometria: Uma visão histórica. Dissertação (Mestrado em Educação: Metodologia do Ensino) Faculdade de Educação, UNICAMP, Campinas/SP.201 p.

ROSA NETO, Ernesto. Didática da matemática. 11. ed. São Paulo: Ática, 1988.

SAITO, Fumikazu; DIAS, Marisa da Silva. Interface entre história da matemática e ensino: uma atividade desenvolvida com base num documento do século XVI. Ciência e Educação. Bauru, n. 1, v. 19, 2013.

SANTOS, D.A.N. A Formação de Professores em de Escola da Rede Pública Estadual em Serviço para o Trabalho com Projetos utilizando as Tecnologias de Informação e Comunicação. Dissertação de Mestrado em Educação. Faculdade de Ciências e Tecnologia UNESP, Presidente Prudente, 2006.

SCHMIDT, G. M.; PRETTO, V.; LEIVAS, J. C. P. História da Matemática como recurso didático-pedagógico para conceitos geométricos. Revista Caderno

Pedagógico: Lajeado. V 13. N 1. 2016.

DE ALMEIDA, Talita Carvalho Silva. Geometria dinâmica: um caminho para o estudo Geometria Espacial - XIII CONFERENCIA INTERAMERICANA DE EDUCAÇÃO MATEMÁTICA - 2011. P.8. 